\title{
Leucocyte telomere length and risk of cardiovascular disease: systematic review and meta-analysis
}

\author{
@) (1) $\Theta$ OPEN ACCESS
}

\author{
Philip C Haycock postdoctoral research assistant ${ }^{12}$, Emma E Heydon doctoral candidate ${ }^{1}$, Stephen \\ Kaptoge senior research associate ${ }^{1}$, Adam S Butterworth university lecturer ${ }^{1}$, Alex Thompson senior \\ epidemiologist $^{13}$, Peter Willeit research associate ${ }^{14}$
}

${ }^{1}$ Cardiovascular Epidemiology Unit, Department of Public Health and Primary Care, Institute of Public Health, University of Cambridge, Strangeways Research Laboratory, Cambridge, UK; ${ }^{2}$ Medical Research Council Integrative Epidemiology Unit, School of Social and Community Medicine, University of Bristol, Bristol, UK; ${ }^{3}$ Roche, Welwyn Garden City, UK; ${ }^{4}$ Department of Neurology, Innsbruck Medical University, Austria

\begin{abstract}
Objective To assess the association between leucocyte telomere length and risk of cardiovascular disease.

Design Systematic review and meta-analysis.

Data sources Studies published up to March 2014 identified through searches of Medline, Web of Science, and Embase.

Eligibility criteria Prospective and retrospective studies that reported on associations between leucocyte telomere length and coronary heart disease (defined as non-fatal myocardial infarction, coronary heart disease death, or coronary revascularisation) or cerebrovascular disease (defined as non-fatal stroke or death from cerebrovascular disease) and were broadly representative of general populations-that is, they did not select cohort or control participants on the basis of pre-existing cardiovascular disease or diabetes.

Results Twenty four studies involving 43725 participants and 8400 patients with cardiovascular disease (5566 with coronary heart disease and 2834 with cerebrovascular disease) were found to be eligible. In a comparison of the shortest versus longest third of leucocyte telomere length, the pooled relative risk for coronary heart disease was 1.54 (95\% confidence interval 1.30 to 1.83 ) in all studies, 1.40 (1.15 to 1.70$)$ in prospective studies, and 1.80 (1.32 to 2.44 ) in retrospective studies. Heterogeneity between studies was moderate $\left(\mathrm{I}^{2}=64 \%, 41 \%\right.$ to $77 \%$, $\mathrm{P}_{\text {het }}<0.001$ ) and was not significantly explained by mean age of participants $(P=0.23)$, the proportion of male participants $(P=0.45)$, or distinction between retrospective versus prospective studies $(P=0.32)$. Findings for coronary heart disease were similar in meta-analyses restricted to studies that adjusted for conventional vascular risk factors (relative risk $1.42,95 \%$ confidence interval 1.17 to 1.73 ); studies with $\geq 200$ cases $(1.44,1.20$ to 1.74$)$; studies with a high quality score (1.53 1.22 to 1.92$)$; and in analyses that corrected for publication bias (1.34,
\end{abstract}

1.12 to 1.60$)$. The pooled relative risk for cerebrovascular disease was 1.42 (1.11 to 1.81 ), with no significant heterogeneity between studies $\left(I^{2}=41 \%, 0 \%\right.$ to $\left.72 \%, P_{\text {het }}=0.08\right)$. Shorter telomeres were not significantly associated with cerebrovascular disease risk in prospective studies $(1.14,0.85$ to 1.54$)$ or in studies with a high quality score $(1.21,0.83$ to 1.76).

Conclusion Available observational data show an inverse association between leucocyte telomere length and risk of coronary heart disease independent of conventional vascular risk factors. The association with cerebrovascular disease is less certain.

\section{Introduction}

Chronological age is one of the strongest predictors of cardiovascular disease but is not considered to be a causal factor. Rather, this relation might reflect the impact of biological ageing, particularly the accumulation of endothelial damage over time, because of various mechanical, haemodynamic, and immunological mechanisms. ${ }^{1}$ Telomeres are DNA-protein structures at the end of linear chromosomes and have been proposed as markers of the biological ageing process because they shorten with each cell division, thereby reflecting the amount of cellular turnover within an individual; their length varies considerably between individuals, including those of the same chronological age; and the rate of attrition of telomere length has been linked to exposure to high oxidative stress and inflammation, both of which are considered important drivers of biological ageing. ${ }^{2}$ In addition, as telomere length within individuals is generally strongly correlated across tissue types, leucocyte based measures might also serve as a marker of telomere length in less accessible tissues. 
Because of its presumed role in biological ageing, telomere length has been proposed as a general risk factor for age related chronic diseases, such as cancer, type 2 diabetes, and cardiovascular disease. ${ }^{5}$ Although previous meta-analyses have shown inverse associations between leucocyte telomere length and cancer and diabetes, ${ }^{6-8}$ the association of telomeres with cardiovascular disease has not yet been systematically assessed. Interpretation of the available evidence for cardiovascular disease has been hindered by studies that used different study designs (such as prospective versus retrospective), application of different assay methods, and/or reporting relative risks for different disease outcomes (such as coronary heart disease or stroke). In addition, many previous studies of telomere length and cardiovascular disease have not reported easily comparable measures of association, such as risk ratios or odds ratios, making their interpretation difficult. Previous studies have also typically been underpowered to assess the association with cardiovascular disease in different population subgroups, such as by age and sex.

We therefore conducted a systematic review and meta-analysis of published studies to assess the association between leucocyte telomere length and cardiovascular disease outcomes. We aimed to precisely quantify any associations in a systematic way and to evaluate and compare these associations across a wide range of study level characteristics.

\section{Methods}

\section{Literature search and study selection}

The meta-analysis was conducted according to the MOOSE guidelines. ${ }^{9}$ We searched for studies that published on associations between leucocyte telomere length and coronary heart disease or cerebrovascular disease in Medline, Web of Science, and Embase up to 20 March 2014 (see fig 1 in appendix). The search strategy combined terms related to telomere length with those related to the outcomes of cardiovascular disease, coronary heart disease, and cerebrovascular disease (see table 1 in appendix) without language restrictions. We complemented the search by scanning reference lists of the identified articles. Studies were eligible for inclusion if they reported on associations between baseline leucocyte telomere length and coronary heart disease (defined as non-fatal myocardial infarction, coronary heart disease death, or coronary revascularisation) or cerebrovascular disease (defined as non-fatal stroke or death from cerebrovascular disease) and were broadly representative of general populations - that is, they did not select participants (in cohort studies) or controls (in case-control studies) on the basis of pre-existing cardiovascular diseases or diabetes. Both prospective and retrospective studies were eligible (where retrospective indicates that telomere length was measured in DNA samples collected after diagnosis of disease). Retrospective studies included case-control and cross sectional studies; prospective studies included nested case-control and prospective cohort studies. Two investigators independently identified eligible studies; discrepancies were resolved by consensus with a third investigator.

\section{Data extraction}

For each article, we used a standardised abstraction form to extract information on geographical location, year of publication, mean and standard deviation of age of participants, proportion of male participants, outcome definition, population source, assay methods, number of experimental replicates, assay coefficient of variation, tissue source of DNA, correlation coefficients between telomere length and age, the mean and standard deviation of telomere length in cases and controls, reported estimates of the association with outcome, and degree of statistical adjustment for covariates. Additional information was obtained through correspondence with study authors. Information on study quality was assessed with the Newcastle-Ottawa scale, which varies from zero to a maximum possible score of nine and incorporates information on participant selection, outcome ascertainment, exposure ascertainment, and the potential for confounding. ${ }^{10}$

\section{Statistical analysis}

The overall cross sectional correlation between telomere length and age was estimated in cohort studies or controls in case-control studies. Study specific correlation coefficients were transformed to approximate normality based on Fisher's z transformation and combined across studies with random effects meta-analysis. When the correlation coefficient was not reported, we estimated it from the $t$ statistic of the linear association between telomere length and age, if available, or contacted authors.

We calculated summary relative risks for the association between telomere length and coronary heart disease or cerebrovascular disease by random effects meta-analysis of study specific estimates. Hazard ratios, risk ratios, and odds ratios were assumed to approximate the same measure of relative risk. The study specific relative risk estimates were transformed to a common scale of comparison before meta-analysis (corresponding to a comparison of risk in the shortest versus longest third of the distribution of telomere length) by using methods previously described. ${ }^{11}$ For example, under the assumption of normality of the distribution of telomere length and a log linear association with disease risk, the log relative risk for the shortest versus longest third of the distribution of telomere length is expected to be about 2.18 times the log relative risk for a $1 \mathrm{SD}$ decrease in telomere length. The standard error of the transformed log relative risk was calculated by applying the same multiplication factor to the originally reported standard error (or that inferred from the reported $P$ value). When they were not reported, we obtained relative risks through correspondence with the study authors or estimated from the mean difference in telomere length between cases and controls, using a previously described method. ${ }^{11}$ For the WTCCC study, ${ }^{12}{ }^{13}$ which did not report a relative risk estimate, we could not derive an estimate based on the preceding approximation because the reported variances of telomere length in cases and controls were markedly different, and this study was therefore excluded. When studies reported relative risks with different degrees of statistical adjustment for confounding, we used the most adjusted estimate. For the WOSCOPS trial, ${ }^{14}$ we used the relative risk estimated from the placebo group. We assessed evidence of publication bias or small study effects using funnel plots and Egger's test ${ }^{15}$ and by comparing pooled results from studies involving $\geq 200$ cases with those from smaller studies. We used Duval's non-parametric "trim and fill" method to estimate the relative risk making allowance for publication bias. $^{16}$

We assessed heterogeneity between studies with Cochran's Q test and the $\mathrm{I}^{2}$ statistic. ${ }^{17}$ Sources of heterogeneity were assessed by comparing results grouped according to study level characteristics and by using meta-regression to assess the significance of differences. Although these results are presented categorically, the $\mathrm{P}$ values from meta-regression on continuous study level characteristics (that is, mean age, age standard deviation, proportion of males, Newcastle-Ottawa scale score, 
assay coefficient of variation, number of experimental replicates, and number of cases) reflect the linear test of association. The study level characteristics tested as sources of heterogeneity were geographical location (Europe versus North America versus Asia), population source (population based versus not), Newcastle-Ottawa scale score, mean age of participants, standard deviation of age of participants (for the correlation between telomere length and age only), proportion of male participants, assay method (quantitative polymerase chain reaction (qPCR) versus others), assay coefficient of variation, DNA extraction method (QiaAMP versus salting out versus other/unspecified), number of assay replicates, number of cases, case definition, and degree of adjustment for covariates, including conventional vascular risk factors (defined as age, sex, body mass index (BMI), smoking, history of diabetes, blood pressure, and lipid markers). All analyses were performed with Stata release 13.1 (StataCorp, College Station, TX). Statistical tests were two sided with a significance threshold of $\mathrm{P}<0.05$.

\section{Results}

The literature search strategy identified 1500 unique articles across Medline, Web of Science, and Embase (see fig 1 in appendix). After the initial screen of titles and abstracts, 76 articles remained for further investigation. We obtained previously unpublished results on stroke from the Scottish Mental Survey through correspondence. After detailed assessments, 26 articles/unpublished reports, corresponding to 24 independent studies, were found to meet the inclusion criteria and were included in the meta-analysis. ${ }^{14}{ }^{18-41}$

The table (and table 2 in the appendix) summarises characteristics of the included studies. $\Downarrow$ In aggregate, the studies involved 43725 individuals, including 8400 cases of cardiovascular disease (5566 with coronary heart disease and 2834 with cerebrovascular disease). Twelve studies had a prospective design (30 510 participants), and 12 had a retrospective design (13215 participants). Twelve studies were conducted in Europe, seven in North America, and five in Asia. Twenty one studies measured telomere length using qPCR (quantitative polymerase chain reaction), whereas two studies used Southern blotting and one used flow-FISH (fluorescent in situ hybridisation). The weighted mean age of participants was 60 (range 40-90), and 53\% were men (range $0-100 \%$ ). Within the included studies, there was a weak inverse correlation between telomere length and chronological age $(r=-0.13,95 \%$ confidence interval -0.18 to -0.08$)$, with substantial heterogeneity between studies $\left(\mathrm{I}^{2}=94 \%, 95 \%\right.$ confidence interval $92 \%$ to $96 \%$ ) (see fig 2 in appendix). The heterogeneity in reported correlations was mostly attributable to the studies' quality, size, and age variability, which collectively explained $80 \%$ of the heterogeneity between studies (residual $\mathrm{I}^{2}=66 \%$ ) (see fig 3 in appendix). The correlation between telomere length and age was -0.22 (95\% confidence interval -0.27 to -0.16 ) in studies with a higher quality score (Newcastle-Ottawa scale score $\geq 8) ;-0.16(-0.22$ to -0.10$)$ in studies with higher age variability (SD of age $\geq 8$ years); and $-0.20(-0.25$ to -0.14$)$ in larger studies $(n>1000)$.

As shown in figure $1 \Downarrow$, the pooled relative risk for coronary heart disease comparing shortest third $v$ longest third of telomere length was 1.54 (95\% confidence interval 1.30 to $1.83 ; 20$ studies), with moderate heterogeneity between studies $\left(\mathrm{I}^{2}=64 \%\right.$, $95 \%$ confidence interval $41 \%$ to $\left.77 \% ; \mathrm{P}_{\text {het }}<0.001\right)$. The pooled relative risk for coronary heart disease was 1.40 (1.15 to 1.70$)$ in prospective studies and 1.80 (1.32 to 2.44 ) in retrospective studies $(\mathrm{P}=0.32$ for difference $)$.
Figure $2 \Downarrow$ shows the results by potential sources of heterogeneity among studies of coronary heart disease, including various clinically relevant subgroups and methodological factors. Pooled relative risk estimates for coronary heart disease did not differ significantly by any of the study level characteristics tested, including geographical location, population source, study quality, mean age, proportion of male participants, assay method, assay coefficient of variation, DNA extraction method, number of experimental replicates, number of cases, case definition, and degree of statistical adjustment (all $\mathrm{P} \geq 0.15$ ). The pooled relative risk for coronary heart disease in the shortest versus longest third of telomere length was 1.59 (95\% confidence interval 1.15 to 2.22 ) in three studies that adjusted for conventional vascular risk factors, 1.34 (1.04 to 1.74) in four studies that adjusted for conventional vascular risk factors plus $\mathrm{C}$ reactive protein and physical activity, and 1.42 (1.17 to 1.73 ) in these seven studies combined. The corresponding association was 1.53 (1.22 to 1.92) in the seven highest quality studies and 1.44 (1.20 to 1.74 ) in eight studies with $\geq 200$ cases.

A funnel plot of the relative risk estimates for coronary heart disease was consistent with the presence of publication bias, which was supported by a significant Egger's regression asymmetry test $(\mathrm{P}<0.001)$ (see fig 4 in appendix). Using the "trim and fill" method, we estimated that in the absence of publication bias, the combined relative risk for coronary heart disease with shorter telomere length would have been 1.34 (95\% confidence interval 1.12 to 1.60 ), weaker than the uncorrected association $(1.54,1.30$ to 1.83$)$ but still significant $(\mathrm{P}=0.001)$.

The pooled relative risk for cerebrovascular disease, for shortest third $v$ longest third of telomere length, using combined information from 10 studies was 1.42 ( $95 \%$ confidence interval 1.11 to 1.81 ), with no significant heterogeneity between studies $\left(\mathrm{I}^{2}=41 \%, 95 \%\right.$ confidence interval $0 \%$ to $72 \% ; \mathrm{P}_{\text {het }}=0.08$ ) (fig $3 \Downarrow)$. The association with cerebrovascular disease remained significant in meta-analyses restricted to four studies that adjusted for conventional vascular risk factors (relative risk $1.54,1.17$ to 2.02 ) and in four studies with $\geq 200$ cases (1.42, 1.05 to 1.92 ) (see fig 5 in appendix). Results of meta-analyses were not significant in the four highest quality studies (1.21, 0.83 to 1.76$)$ nor in six prospective studies $(1.14,0.85$ to 1.54$)$ (fig $3 \Downarrow$ and fig 5 in appendix). There was little evidence of publication bias among studies of cerebrovascular disease $\left(\mathrm{P}_{\text {Egger }}=0.64\right)$.

\section{Discussion}

\section{Principal findings}

This meta-analysis indicates that telomere length is inversely associated with risk of coronary heart disease independently of conventional vascular risk factors. The association was broadly consistent across all study level characteristics tested, including clinically relevant subgroups, such as different mean ages and sex distribution, and across prospective and retrospective studies. In addition, the association with coronary heart disease remained significant in analyses that made allowance for publication bias and in analyses restricted to studies with comprehensive adjustment for potential confounders, in larger studies (that is, those with $\geq 200$ cases), and in the studies with a higher quality score.

The association between shorter telomeres and cerebrovascular disease was comparable with the association with coronary heart disease. It was not, however, significant in meta-analyses restricted to prospective studies or the higher quality studies. Further well powered prospective studies are required to clarify 
the association between telomere length and cerebrovascular disease.

Finally, there was an inverse correlation in our meta-analysis between telomere length and age that was weaker than the correlation reported in a previous systematic review ${ }^{42}(r=-0.13$ $v r=-0.30$ ). This could be because of differences among the studies included in the two reviews. For example, we observed that the correlation with age was stronger in studies of higher quality, more variable age, and larger size.

\section{Association or causation}

There was a significant inverse association between telomere length and coronary heart disease in studies that used comprehensive statistical adjustment for potential confounders. As our meta-analysis was based on results from observational studies, however, the association could still be subject to residual confounding or reverse causation bias and therefore does not allow inference of a cause-effect association. In a recent meta-analysis of 14 genome-wide association studies (GWAS), ${ }^{43}$ involving up to 22233 people with coronary heart disease and 64762 controls of European descent, seven single nucleotide polymorphisms (SNPs) were identified that each explained $<1 \%$ of the variation in mean leucocyte telomere length. When all seven polymorphisms were combined into a single genetic risk score, the alleles associated with shorter telomere length were also associated with increased risk of coronary heart disease. The reported genetic effect would be equivalent to a relative risk of 1.67 (95\% confidence interval 1.12 to 2.56) in the shortest versus longest third of the telomere length distribution. As genotypes are randomly determined at conception and are therefore not generally susceptible to reverse causation bias and confounding, ${ }^{44}$ estimates from genetic analyses can be viewed as causal. The genetic effect estimate is compatible with the observational estimate of 1.54 (1.30 to 1.83 ) in our meta-analysis.

As to the mechanisms of a causal association, telomere shortening might contribute to atherosclerosis through various biological ageing pathways, such as cellular senescence. For example, the accumulation of senescent cells, a prominent feature of atherosclerotic plaques, reduces the regenerative potential of affected tissues and promotes apoptosis, which can further exacerbate inflammatory reactions, and endothelial dysfunction. ${ }^{45}{ }^{46}$ It has also been hypothesised that, by reducing the proliferative potential of vascular smooth muscle cells, cellular senescence promotes the thinning of fibrous caps and the instability of atherosclerotic plaques. ${ }^{47}$ As to potential therapeutic interventions to modify telomere length, ectopic expression of telomerase or telomerase reverse transcriptase can reverse some of the effects of cellular senescence, such as the loss of the proliferative potential of vascular smooth muscle cells and endothelial dysfunction. ${ }^{45} 47$

\section{Strengths and limitations}

As far as we are aware, this is the first systematic review and meta-analysis of the association between telomere length and risk of coronary heart disease and cerebrovascular disease in general populations. The existence of widely varying methods for reporting associations in the literature has made comparing results across studies challenging. By harmonising the reported associations across studies to a common scale, however, we were able to quantify the magnitude of the association between telomere length and cardiovascular disease in general populations, to explore sources of heterogeneity between studies, and to estimate the potential impact of publication bias.
Our review also has some limitations. Firstly, the results of this meta-analysis were based on telomere length measured in blood leucocytes, and telomere shortening in more relevant tissues, such as the vasculature, might show stronger associations with coronary heart disease. Nevertheless, telomere length within individuals is generally strongly correlated across tissues, suggesting that leucocyte measures accurately reflect the same construct in other tissues. ${ }^{4}$ Secondly, we were unable to test the shape of the association between telomere length and coronary heart disease or cerebrovascular disease. If the association were non-linear, telomere length at different thresholds might show stronger associations. Thirdly, our results reflect the measurement of telomere length at a single time point, and longitudinal changes in telomere length might show stronger associations with risk of cardiovascular disease. ${ }^{22}{ }^{48}$ Fourthly, the results of the included studies reflect average telomere length measured across all chromosomes. Measurement of telomere length of individual chromosomes might be more important, as telomeric dysfunction of one chromosome is sufficient to induce cell apoptosis. ${ }^{49}$ Such detailed measurements, however, are currently not feasible in large scale epidemiological studies. Fifthly, our meta-analysis was limited to aggregate data obtained from the published literature and through correspondence. Access to individual participant data would allow detailed characterisation of the shape of any dose-response relations, consistent statistical adjustment for potential confounders across studies, direct comparison of telomere length with traditional cardiovascular risk factors, assessment of the associations of telomere length in different population subgroups, and exploration of the usefulness of telomere length in prediction of risk of cardiovascular disease by calculation of risk prediction metrics, such as risk discrimination and risk reclassification.

\section{Should measurement of telomere length be offered as a marker of age related chronic diseases?}

In 2010, two companies in the United States and Spain were founded that offer telomere length measurement services, claiming that shorter telomere length is a reliable marker of many age related chronic diseases. By 2013, one company (www.lifelength.com) offered measurement to the general public (through a requesting physician or laboratory) and the other (www.telomeredx.com) stated they intended to do so soon. Whether telomere testing can provide reliable information about risk of chronic disease to individuals from the general population, however, has not been firmly established.$^{6-8}{ }^{50}$ For example, in a meta-analysis involving 26 studies and 11255 patients with cancer, telomere length was not associated with cancer risk in the subset of studies with a prospective design. In our meta-analysis, shorter telomeres were associated with coronary heart disease under a wide range of circumstances, but the association with cerebrovascular disease did not persist in prospective studies or the highest quality studies. Although our meta-analysis suggests that telomere length is an independent risk factor for coronary heart disease, judgment on whether it is a clinically useful predictor of risk that can help guide treatment decisions will require formal evaluation of its predictive value in large prospective studies with long follow-up.

\section{Conclusions}

Available observational data show an inverse association between telomere length and risk of coronary heart disease, independent of conventional vascular risk factors. The association with cerebrovascular disease is less certain. Additional meta-analyses based on individual participant data 
are required to characterise the shape of any dose-response associations, to further characterise the nature of the association in different population subgroups, and to explore the usefulness of telomere length in prediction of risk of cardiovascular disease.

We gratefully acknowledge the assistance of Sharon Stein Merkin (David Geffen School of Medicine at UCLA), loakim Spyridopoulos (Newcastle University, Institute of Genetic Medicine), Andrie Panayiotou (Cyprus International Institute for Environmental and Public Health in association with the Harvard School of Public Health, Cyprus University of Technology), John M Starr (Centre for Cognitive Ageing and Cognitive Epidemiology, University of Edinburgh), Cécilia Maubaret

(Cardiovascular Genetics BHF Laboratories, University College London), Jackie A Cooper (Centre for Cardiovascular Genetics, University College London), Katarina Nordfjäll (department of medical biosciences,

Pathology, Umeå University) and Göran Roos (department of medical biosciences, Pathology, Umeå University), Richard Cawthon (department of human genetics, University of Utah), Russell P Tracy (department of pathology, University of Vermont), and Anja Jochumsen (department of clinical biochemistry, Copenhagen University Hospital) who provided additional information about their studies for inclusion in this meta-analysis. Emanuele Di Angelantonio (department of public health and primary care, University of Cambridge) and Julia Gumy (school of social policy, sociology and social research, University of Kent) commented helpfully on the manuscript. No financial compensation was provided for any contributions or assistance.

Contributors: PCH, EEH, PW, and AT were involved in the design of the study; $\mathrm{PCH}, \mathrm{EEH}$, and PW acquired data from selected studies; all authors were involved in the analysis and interpretation of the data; $\mathrm{PCH}, \mathrm{EEH}$, and PW drafted the manuscript; all authors provided critical revision of the manuscript for important intellectual content; $\mathrm{PCH}$ carried out the statistical analyses; $\mathrm{PCH}$ is guarantor. AT and PW contributed equally.

Funding: The Cardiovascular Epidemiology Unit is supported by a core grant from the British Heart Foundation (RG/13/13/30194) and the UK Medical Research Council (MR/L003120/1).

Competing interests: All authors have completed the Unified Competing Interest form at www.icmje.org/coi_disclosure.pdf (available on request from the corresponding author) and declare: $\mathrm{PCH}$ and $\mathrm{EEH}$ were supported by Medical Research Council studentships; SK has received research funding from the British Heart Foundation, Medical Research Council, UK National Institute of Health Research and Cambridge Biomedical Research Centre; AT has received research funding from the British Heart Foundation and Medical Research Council; PW was supported by a non-clinical PhD studentship from the British Heart Foundation; no support was received from any organisation for the submitted work; there were no financial relationships with any organizations that might have an interest in the submitted work in the previous three years; there were no other relationships or activities that could appear to have influenced the submitted work.

Ethical approval: Not required.

Transparency: PCH affirms that the manuscript is an honest, accurate, and transparent account of the study being reported and that no important aspects of the study have been omitted. All authors had full access to all of the data (including statistical reports and tables) in the study and can take responsibility for the integrity of the data and the accuracy of the data analysis.

Data sharing: No additional data available.

1 Balasubramanyam M, Adaikalakoteswari A, Monickaraj SF, Mohan V. Telomere shortening and metabolic/vascular diseases. Indian J Med Res 2007;125:441-50.

2 Samani NJ, van der Harst P. Biological ageing and cardiovascular disease. Heart 2008:94:537-9.

3 Mather KA, Jorm AF, Parslow RA, Christensen $\mathrm{H}$. Is telomere length a biomarker of aging? A review. J Gerontol A Biol Sci Med Sci 2011;66:202-13

4 Takubo K, Izumiyama-Shimomura N. Telomere lengths are characteristic in each human individual. Exp Gerontol 2002;37:523-31.
5 Sanders JL, Newman AB. Telomere length in epidemiology: a biomarker of aging, age-related disease, both, or neither? Epidemiol Rev 2013;35:112-31

6 Wentzensen IM, Mirabello L, Pfeiffer RM, Savage SA. The association of telomere length and cancer: a meta-analysis. Cancer Epidemiol Biomarkers Prev 2011;20:1238-50.

7 Ma H, Zhou Z, Wei S, Liu Z, Pooley K. Shortened telomere length is associated with increased risk of cancer: a meta-analysis. PLoS One 2011;6:e20466.

8 Zhao J, Miao K, Wang H, Ding H, Wang DW. Association between telomere length and type 2 diabetes mellitus: a meta-analysis. PLoS One 2013:8:e79993.

9 Stroup DF, Berlin JA, Morton SC, Olkin I, Williamson GD, Rennie D, et al. Meta-analysis of observational studies in epidemiology: a proposal for reporting. JAMA 2000;283:2008-12.

10 Wells G, Shea B, O'Connell D, Peterson J, Welch V, Losos M, et al. The Newcastle-Ottawa Scale (NOS) for assessing the quality of nonrandomised studies in meta-analyses. Ottawa Hospital Research Institute. www.ohri.ca/programs/clinical_epidemiology/oxford.asp

11 Chene G, Thompson SG. Methods for summarizing the risk associations of quantitative variables in epidemiologic studies in a consistent form. Am J Epidemiol 1996;144:610-21.

12 Codd V, van der Harst P, Rafelt S, Hall AS, Samani NJ. The association of the chromosome 9 p21 locus on risk of coronary artery disease is not mediated via an effect on telomere length. Heart 2009;95(suppl I):135.

13 Codd V, Mangino M, van der Harst P, Braund PS, Kaiser M, Beveridge AJ, et al. Common variants near TERC are associated with mean telomere length. Nat Genet 2010;42:197-9.

14 Brouilette SW, Moore JS, McMahon AD, Thompson JR, Ford I, Shepherd J, et al. Telomere length, risk of coronary heart disease, and statin treatment in the West of Scotland Primary Prevention Study: a nested case-control study. Lancet 2007;369:107-14.

15 Egger M, Davey Smith G, Schneider M, Minder C. Bias in meta-analysis detected by a simple, graphical test. BMJ 1997;315:629-34.

16 Duval S, Tweedie R. A nonparametric "trim and fill" method of accounting for publication bias in meta-analysis. J Am Stat Assoc 2000;95:89-98.

17 Higgins JPT, Thompson SG. Quantifying heterogeneity in a meta-analysis. Stat Med 2002;21:1539-58

18 Brouilette S, Singh RK, Thompson JR, Goodall AH, Samani NJ. White cell telomere length and risk of premature myocardial infarction. Arterioscler Thromb Vasc Biol 2003;23:842-6.

19 Cawthon RM, Smith KR, O'Brien E, Sivatchenko A, Kerber RA. Association between telomere length in blood and mortality in people aged 60 years or older. Lancet 2003;361:393-5.

20 Cui G, Sun J, Zhang L, Li R, Wang Y, Cianflone K, et al. Lack of causal relationship between leukocyte telomere length and coronary heart disease. Atherosclerosis 2014;233:375-80.

21 Ding H, Chen C, Shaffer JR, Liu L, Xu Y, Wang X, et al. Telomere length and risk of stroke in Chinese. Stroke 2012;43:658-63.

22 Epel ES, Merkin SS, Cawthon R, Blackburn EH, Adler NE, Pletcher MJ, et al. The rate of leukocyte telomere shortening predicts mortality from cardiovascular disease in elderly men. Aging (Albany NY) 2008;1:81-8.

23 Fitzpatrick AL, Kronmal RA, Gardner JP, Psaty BM, Jenny NS, Tracy RP, et al. Leukocyte telomere length and cardiovascular disease in the cardiovascular health study. Am J Epidemiol 2007;165:14-21.

24 Fitzpatrick AL, Kronmal RA, Kimura M, Gardner JP, Psaty BM, Jenny NS, et al. Leukocyte telomere length and mortality in the Cardiovascular Health Study. J Gerontol A Biol Sci Med Sci 2011;66:421-9.

25 Jiang X, Dong M, Cheng J, Huang S, He Y, Ma K, et al. Decreased leukocyte telomere length (LTL) is associated with stroke but unlikely to be causative. PLoS One 2013;8:e68254.

26 Martin-Ruiz CM, Gussekloo J, van Heemst D, von Zglinicki T, Westendorp RG. Telomere length in white blood cells is not associated with morbidity or mortality in the oldest old: a population-based study. Aging Cell 2005;4:287-90.

27 Maubaret CG, Salpea KD, Jain A, Cooper JA, Hamsten A, Sanders J, et al. Telomeres are shorter in myocardial infarction patients compared to healthy subjects: correlation with environmental risk factors. J Mol Med (Berl) 2010:88:785-94.

28 Mukherjee M, Brouilette S, Stevens S, Shetty KR, Samani NJ. Association of shorter telomeres with coronary artery disease in Indian subjects. Heart 2009;95:669-73.

29 Njajou OT, Hsueh W-C, Blackburn EH, Newman AB, Wu S-H, Li R, et al. Association between telomere length, specific causes of death, and years of healthy life in health, aging, and body composition, a population-based cohort study. J Gerontol A Biol Sci Med Sci 2009:64:860-4.

30 Nordfjäll K, Osterman P, Melander O, Nilsson P, Roos G. hTERT (-1327)T/C polymorphism is not associated with age-related telomere attrition in peripheral blood. Biochem Biophys Res Commun 2007;358:215-8

31 Panayiotou A, Nicolaides A, Griffin M, Tyllis T, Georgiou N, Bond D, et al. Leukocyte telomere length is associated with measures of subclinical atherosclerosis. Atherosclerosis 2010;211:176-81

32 Russo A, Palumbo L, Fornengo C, Di Gaetano C, Ricceri F, Guarrera S, et al. Telomere length variation in juvenile acute myocardial infarction. PLOS One 2012;7:e49206.

33 Schürks M, Prescott J, Dushkes R, De Vivo I, Rexrode KM. Telomere length and ischaemic stroke in women: a nested case-control study. Eur J Neurol 2013;20:1068-74.

34 Spyridopoulos I, Hoffmann J, Aicher A, Brümmendorf TH, Doerr HW, Zeiher AM, et al. Accelerated telomere shortening in leukocyte subpopulations of patients with coronary heart disease: role of cytomegalovirus seropositivity. Circulation 2009;120:1364-72.

35 Starr JM, McGurn B, Harris SE, Whalley LJ, Deary IJ, Shiels PG. Association between telomere length and heart disease in a narrow age cohort of older people. Exp Gerontol 2007:42:571-3.

36 Weischer M, Bojesen SE, Cawthon RM, Freiberg JJ, Tybjærg-Hansen A, Nordestgaard BG. Short telomere length, myocardial infarction, ischemic heart disease, and early death Arterioscler Thromb Vasc Biol 2012;32:822-9.

37 Willeit P, Willeit J, Brandstätter A, Ehrlenbach S, Mayr A, Gasperi A, et al. Cellular aging reflected by leukocyte telomere length predicts advanced atherosclerosis and cardiovascular disease risk. Arterioscler Thromb Vasc Biol 2010;30:1649-56.

38 Ye S, Shaffer JA, Kang MS, Harlapur M, Muntner P, Epel E, et al. Relation between leukocyte telomere length and incident coronary heart disease events (from the 1995 Canadian Nova Scotia Health Survey). Am J Cardiol 2013;111:962-7.

39 Zee RYL, Michaud SE, Germer S, Ridker PM. Association of shorter mean telomere length with risk of incident myocardial infarction: a prospective, nested case-control approach. Clin Chim Acta 2009;403:139-41.

40 Zee RYL, Castonguay AJ, Barton NS, Ridker PM. Relative leukocyte telomere length and risk of incident ischemic stroke in men: a prospective, nested case-control approach. Rejuvenation Res 2010;13:411-4. 


\section{What is already known on this topic}

Because of its presumed role in biological ageing, telomere length has been proposed as a marker of age related chronic diseases There is conflicting evidence in the literature on the association between telomere length and cardiovascular disease

\section{What this study adds}

Observational evidence from this meta-analysis shows that shorter leucocyte telomeres are associated with risk of coronary heart disease in general populations, independently of conventional vascular risk factors

The association with cerebrovascular disease is less certain

41 Zhang W, Chen Y, Wang Y, Liu P, Zhang M. Short telomere length in blood leukocytes contributes to the presence of atherothrombotic stroke and hemorrhagic stroke and risk contributes to the presence of atherothrombotic
of post-stroke death. Clin Sci 2013;125:27-36.

42 Müezzinler A, Zaineddin AK, Brenner H. A systematic review of leukocyte telomere length and age in adults. Ageing Res Rev 2013;12:509-19.

43 Codd V, Nelson CP, Albrecht E, Mangino M, Deelen J, Buxton JL, et al. Identification of seven loci affecting mean telomere length and their association with disease. Nat Genet 2013;45:422-7.

44 Davey Smith G, Ebrahim S. "Mendelian randomization": can genetic epidemiology contribute to understanding environmental determinants of disease? Int J Epidemiol 2003;32:1-22.

45 Minamino T, Miyauchi H, Yoshida T, Ishida Y, Yoshida H, Komuro I. Endothelial cell senescence in human atherosclerosis: role of telomere in endothelial dysfunction. Circulation 2002;105:1541-4.

46 Matthews C, Gorenne I, Scott S, Figg N, Kirkpatrick P, Ritchie A, et al. Vascular smooth muscle cells undergo telomere-based senescence in human atherosclerosis: effects of telomerase and oxidative stress. Circ Res 2006;99:156-64.

47 Gorenne I, Kavurma M, Scott S, Bennett M. Vascular smooth muscle cell senescence in atherosclerosis. Cardiovasc Res 2006;72:9-17.
48 Weischer M, Bojesen SE, Nordestgaard BG. Telomere shortening unrelated to smoking body weight, physical activity, and alcohol intake: 4,576 general population individuals with repeat measurements 10 years apart. PLoS Genet 2014;10:e1004191.

49 Hemann MT, Strong MA, Hao LY, Greider CW. The shortest telomere, not average telomere length, is critical for cell viability and chromosome stability. Cell 2001;107:67-77. 50 McCartney M. Would you like your telomeres tested? BMJ 2012;344:e681.

Accepted: 12 June 2014

\section{Cite this as: BMJ 2014;349:g4227}

This is an Open Access article distributed in accordance with the Creative Commons Attribution Non Commercial (CC BY-NC 3.0) license, which permits others to distribute, remix, adapt, build upon this work non-commercially, and license their derivative works on different terms, provided the original work is properly cited and the use is non-commercial. See: http://creativecommons.org/licenses/by-nc/3.0/. 


\section{Table}

Table 1 | Selected characteristics of 24 vascular disease studies included in review of leucocyte telomere length and risk of cardiovascular disease

\begin{tabular}{|c|c|c|c|c|c|c|c|c|c|c|c|}
\hline & Location & $\begin{array}{l}\text { Population source } \\
\text { (overall or of cases } \\
\text { / controls) }\end{array}$ & $\begin{array}{l}\text { NOS } \\
\text { quality } \\
\text { score }\end{array}$ & $\begin{array}{l}\text { Mean age } \\
\text { (SD) }\end{array}$ & Men (\%) & $\begin{array}{l}\text { Assay } \\
\text { method }\end{array}$ & $\begin{array}{c}\text { CHD } \\
\text { definition }\end{array}$ & $\begin{array}{c}\text { CEVD } \\
\text { definition }\end{array}$ & $\begin{array}{l}\text { Cohort } \\
\text { size or No } \\
\text { of controls }\end{array}$ & $\begin{array}{l}\text { No of } \\
\text { CHD } \\
\text { cases }\end{array}$ & $\begin{array}{l}\text { No of } \\
\text { CEVD } \\
\text { cases }\end{array}$ \\
\hline \multicolumn{12}{|c|}{ Prospective studies } \\
\hline BRUNECK $^{37}$ & Italy & $\begin{array}{l}\text { Population based } \\
\text { cohort }\end{array}$ & 9 & $62.7(11.1)$ & 49 & qPCR & Mixed & $\begin{array}{l}\text { Ischaemic } \\
\text { stroke }\end{array}$ & 800 & 43 & 46 \\
\hline Cawthon ${ }^{19}$ & US & Family linkage study & 4 & $71.5(7.9)$ & 50 & qPCR & Fatal & Unclassified & 124 & 30 & 15 \\
\hline $\mathrm{CCHS}^{36}$ & Denmark & $\begin{array}{l}\text { Population based } \\
\text { cohort }\end{array}$ & 8 & $59.0(16.7)$ & 45 & qPCR & Mixed & - & 9765 & 699 & - \\
\hline CGPS $^{36}$ & Denmark & $\begin{array}{l}\text { Population based } \\
\text { cohort }\end{array}$ & 8 & $56.5(13.5)$ & 48 & qPCR & Mixed & - & 10073 & 230 & - \\
\hline $\mathrm{CHS}^{23}$ & US & Insurance register & 8 & $74.4(5.2)$ & 41 & SB & Mixed & - & 419 & 36 & - \\
\hline $\mathrm{CHS}^{24}$ & us & Insurance register & 8 & $73.9(4.7)$ & 35 & SB & - & $\begin{array}{l}\text { Ischaemic } \\
\text { stroke }\end{array}$ & 1004 & - & 43 \\
\hline $\mathrm{HABC}^{29}$ & US & $\begin{array}{l}\text { Insurance register } \\
\text { and area code } \\
\text { residence }\end{array}$ & 7 & $73.6(2.9)$ & 49 & qPCR & Fatal & Unclassified & 2721 & 189 & 69 \\
\hline MAHAS 22 & US & $\begin{array}{l}\text { High functioning } \\
\text { subset of EPESE }\end{array}$ & 3 & $73.7(2.9)$ & 49 & qPCR & Fatal & - & 235 & 29 & - \\
\hline $\mathrm{MDC}^{30}$ & Sweden & $\begin{array}{l}\text { Population based } \\
\text { cohort }\end{array}$ & 7 & $61.0(5.1)$ & 69 & qPCR & Mixed & - & $444^{*}$ & 226 & - \\
\hline $\mathrm{NHS}^{33}$ & USA & Occupational list & 8 & $61.4(5.9)$ & 0 & qPCR & - & $\begin{array}{l}\text { Ischaemic } \\
\text { stroke }\end{array}$ & $392^{*}$ & - & 392 \\
\hline NSHS95 ${ }^{38}$ & Canada & $\begin{array}{l}\text { Population based } \\
\text { cohort }\end{array}$ & 8 & $46.6(18.4)$ & 49 & qPCR & Mixed & - & 1917 & 164 & - \\
\hline $\mathrm{PHS}^{40}$ & US & Occupational list & 8 & $61.7(7.9)$ & 100 & qPCR & - & $\begin{array}{l}\text { Ischaemic } \\
\text { stroke }\end{array}$ & $259^{*}$ & - & 259 \\
\hline $\mathrm{PHS}^{39}$ & US & Occupational list & 8 & $60.1(8.7)$ & 100 & qPCR & Mixed & - & $337^{*}$ & 337 & - \\
\hline WOSCOPS $^{14}$ & Scotland & GP register & 8 & $56.7(5.2)$ & 100 & qPCR & Mixed & - & $517^{*}$ & 289 & - \\
\hline \multicolumn{12}{|c|}{ Retrospective studies } \\
\hline Brouilette $^{18}$ & UK & $\begin{array}{l}\text { Hospital register/GP } \\
\text { register }\end{array}$ & 5 & $47.2(5.9)$ & 86 & SB & Non-fatal & - & $180^{*}$ & 203 & - \\
\hline $\mathrm{Cui}^{20}$ & China & $\begin{array}{l}\text { Hospital } \\
\text { patients/community } \\
\text { sample }\end{array}$ & 7 & $58.6(9.4)$ & 54 & qPCR & Non-fatal & - & $2211^{*}$ & 2140 & - \\
\hline CYPRUS 31 & Cyprus & $\begin{array}{l}\text { Population based } \\
\text { cohort }\end{array}$ & 7 & $60.5(10.2)$ & 47 & qPCR & Non-fatal & - & 762 & 42 & - \\
\hline Ding $^{21}$ & China & $\begin{array}{l}\text { Hospital } \\
\text { patients/community } \\
\text { sample }\end{array}$ & 7 & $61.4(9.8)$ & 66 & qPCR & - & $\begin{array}{l}\text { Ischaemic } \\
\text { stroke }\end{array}$ & $1081^{*}$ & - & 1081 \\
\hline $\mathrm{HIFMECH}^{27}$ & Multiple† & $\begin{array}{l}\text { Hospital } \\
\text { patients/community } \\
\text { sample }\end{array}$ & 6 & $51.5(5.5)$ & 100 & qPCR & Non-fatal & - & $559^{*}$ & 520 & - \\
\hline Jiang $^{25}$ & China & $\begin{array}{l}\text { Hospital } \\
\text { patients/community } \\
\text { sample }\end{array}$ & 6 & $52.2(8.1)$ & 74 & qPCR & - & $\begin{array}{l}\text { Ischaemic } \\
\text { stroke }\end{array}$ & $150^{*}$ & - & 150 \\
\hline $\mathrm{L} 85+^{26}$ & Netherlands & $\begin{array}{l}\text { Population based } \\
\text { cohort }\end{array}$ & 4 & $89.7(3.0)$ & 27 & qPCR & Non-fatal & - & 679 & 51 & - \\
\hline MCSS $^{41}$ & China & $\begin{array}{l}\text { Hospital } \\
\text { patients/hospital } \\
\text { patients }\end{array}$ & 6 & $59.7(8.2)$ & 57 & qPCR & - & $\begin{array}{l}\text { Ischaemic } \\
\text { stroke }\end{array}$ & $1801^{*}$ & - & 767 \\
\hline Mukherjee ${ }^{28}$ & India & $\begin{array}{l}\text { Hospital } \\
\text { patients/community } \\
\text { sample }\end{array}$ & 5 & $56.9(11.0)$ & 78 & qPCR & Non-fatal & - & $238^{*}$ & 76 & - \\
\hline
\end{tabular}


(continued)

\begin{tabular}{|c|c|c|c|c|c|c|c|c|c|c|c|}
\hline & Location & $\begin{array}{c}\text { Population source } \\
\text { (overall or of cases } \\
\text { / controls) }\end{array}$ & $\begin{array}{l}\text { NOS } \\
\text { quality } \\
\text { score }\end{array}$ & $\begin{array}{l}\text { Mean age } \\
\text { (SD) }\end{array}$ & Men (\%) & $\begin{array}{l}\text { Assay } \\
\text { method }\end{array}$ & $\begin{array}{c}\text { CHD } \\
\text { definition }\end{array}$ & $\begin{array}{c}\text { CEVD } \\
\text { definition }\end{array}$ & $\begin{array}{l}\text { Cohort } \\
\text { size or No } \\
\text { of controls }\end{array}$ & $\begin{array}{l}\text { No of } \\
\text { CHD } \\
\text { cases }\end{array}$ & $\begin{array}{l}\text { No of } \\
\text { CEVD } \\
\text { cases }\end{array}$ \\
\hline Russo ${ }^{32}$ & Italy & $\begin{array}{l}\text { Hospital } \\
\text { patients/unspecified }\end{array}$ & 6 & $39.8(5.0)$ & 91 & qPCR & Non-fatal & - & $190^{*}$ & 199 & - \\
\hline SMS $\ddagger^{35}$ & UK & $\begin{array}{l}\text { Population based } \\
\text { cohort }\end{array}$ & 5 & $79.0(0)$ & 82 & qPCR & Non-fatal & Unclassified & 190 & 38 & 12 \\
\hline Spyridopoulos ${ }^{34}$ & Germany & $\begin{array}{l}\text { Hospital } \\
\text { patients/volunteers }\end{array}$ & 3 & $65.1(2.1)$ & 100 & FISH & Non-fatal & - & $13^{*}$ & 25 & - \\
\hline
\end{tabular}

$\mathrm{CEVD}=$ cerebrovascular disease; $\mathrm{CHD}=$ coronary heart disease; $\mathrm{FISH}=$ flow cytometry-fluorescent in situ hybridisation; NOS= Newcastle-Ottawa scale; qPCR= quantitative polymerase chain reaction; $\mathrm{SB}=$ Southern blotting; $\mathrm{CCHS}=$ Copenhagen City Heart Study; CGPS=Copenhagen General Population Study;

$\mathrm{CHS}=$ Cardiovascular Health Study; EPESE=Established Populations for the Epidemiologic Study of the Elderly; HABC=Health Aging and Body Composition Study; HIFMECH=Hypercoagulability and Impaired Fibrinolytic function MECHanisms predisposing to myocardial infarction; L85+=Leiden 85-plus study; MAHAS=MacArthur Health Aging Study; MCSS=Multicenter Chinese Stroke Study; MDC=Malmö Diet and Cancer Study; NHS=Nurses' Health Study; NSHS95=1995 Nova Scotia Health Survey; PHS=Physicians' Health Study; SMS=Scottish Mental Survey; WOSCOPS=West of Scotland Coronary Prevention Study.

${ }^{*}$ Number of controls in case-control study.

†Sweden, England, France, Italy.

‡Findings for CEVD previously unpublished. 


\section{Figures}

\begin{tabular}{|c|c|c|c|c|}
\hline Design/study & $\begin{array}{c}\text { Degree of } \\
\text { adjustment }\end{array}$ & $\begin{array}{l}\text { No of } \\
\text { cases }\end{array}$ & $\begin{array}{c}\text { Relative risk } \\
(95 \% \mathrm{Cl})\end{array}$ & $\begin{array}{l}\text { Relative risk }(95 \% \mathrm{Cl}) \\
\text { for } \mathrm{CHD} \text { comparing } \\
\text { shortest } v \text { longest third } \\
\text { of telomere length }\end{array}$ \\
\hline Spyridopoulos 34 & + & 25 & & $580(071$ to 47 19)t \\
\hline $\mathrm{SMS}^{35}$ & $\begin{array}{l}+ \\
+\end{array}$ & 23 & & $3.80(0.11(047.19) 1$ \\
\hline CYPRUS ${ }^{31}$ & $\begin{array}{c}+ \\
+++\end{array}$ & 30 & & $4.18(2.20 \text { to } 10.31)^{n} \mathrm{~T}$ \\
\hline $85+26$ & +++ & 42 & & $1.98(0.86$ to 3.91$)$ \\
\hline 28 & + & 31 & & $2.23(1.06$ 10 4.66) \\
\hline Mukherjee ${ }^{20}$ & - & 76 & & $2.15(1.23 \text { to } 3.78)^{x}$ \\
\hline Russo $^{32}$ & + & 199 & & $0.89(0.58 \text { to } 1.38)^{*}$ \\
\hline Brouilette $^{18}$ & ++ & 203 & & 2.41 (1.44 to 4.05$)$ \\
\hline $\mathrm{HIFMECH}^{27}$ & ++ & 520 & & $1.37(1.00$ to 1.89$) \dagger$ \\
\hline $\mathrm{Cui}^{2 \mathrm{O}}$ & +++ & 2140 & & 1.31 (1.04 to 1.89$)$ \\
\hline Subtotal (9 studies & & 3294 & & 1.80 (1.32 to 2.44$)$ \\
\hline \multicolumn{5}{|c|}{ Heterogeneity: $I^{2}=65 \%$ ( $30 \%$ to $\left.83 \%\right)$} \\
\hline \multicolumn{5}{|c|}{ Prospective studies } \\
\hline MAHAS $^{22}$ & - & 29 & & $1.09(0.47 \text { to } 2.54)^{*} \dagger$ \\
\hline Cawthon $^{19}$ & + & 30 & & $4.86(1.52$ to 15.57$)$ \\
\hline $\mathrm{CHS}^{23}$ & ++ & 36 & & 1.47 (0.87 to 2.48$)$ \\
\hline BRUNECK ${ }^{37}$ & ++++ & 43 & & $3.52(1.29$ to 9.57$) \dagger$ \\
\hline NSHS95 $5^{38}$ & ++++ & 164 & & $1.25(0.82$ to 1.90$)$ \\
\hline $\mathrm{HABC}^{29}$ & ++ & 189 & & $1.00(0.76$ to 1.29$)$ \\
\hline $\mathrm{MDC}^{30}$ & + & 226 & & $1.00(0.71 \text { to } 1.42)^{*} \dagger$ \\
\hline $\mathrm{CGPS}^{36}$ & ++++ & 230 & & $1.48(1.03$ to 2.11$)$ \\
\hline WOSCOPS $^{14}$ & ++ & 289 & & 1.95 (1.33 to 2.84$)$ \\
\hline $\mathrm{PHS}^{39}$ & +++ & 337 & $=$ & 2.11 (1.22 to 3.64$)$ \\
\hline $\mathrm{CCHS}^{36}$ & ++++ & 699 & & $1.16(0.98$ to 1.36$)$ \\
\hline Subtotal (11 studie & & 2272 & 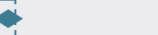 & $1.40(1.15$ to 1.70$)$ \\
\hline \multicolumn{5}{|c|}{ Heterogeneity: $\left.\right|^{2}=59 \%$ ( $21 \%$ to $79 \%$ ) } \\
\hline Total (20 studies): & $\%(41 \%$ to $77 \%)$ & 5566 & $<$ & $1.54(1.30$ to 1.83$)$ \\
\hline
\end{tabular}

Fig 1 Shorter telomere length and risk of coronary heart disease across 20 studies stratified by study design (see table for study acronyms). Study specific estimates were pooled with random effects meta-analysis. Sizes of data markers are proportional to inverse of variance within study. Degree of adjustment: - no adjustment, + adjusted for age and/or sex, ++ adjusted for age, sex, and non-lipid risk factors, +++ adjusted for age, sex, smoking, BMl, diabetes, blood pressure, and lipid markers; ++++ preceding plus adjusted for $C$ reactive protein and physical activity. ${ }^{*}$ Calculated from mean difference in telomere length between cases and controls; †obtained through correspondence. Summary associations for prospective and retrospective studies were not significantly different $(P=0.32)$ 


\begin{tabular}{|c|c|c|c|c|c|}
\hline Genoraphical lecat & $\begin{array}{c}\text { No of } \\
\text { studies }\end{array}$ & $\begin{array}{l}\text { No of } \\
\text { cases }\end{array}$ & $\begin{array}{c}\text { Relative risk } \\
(95 \% \mathrm{CI})\end{array}$ & $\begin{array}{l}\text { Relative risk ( } 95 \% \mathrm{Cl}) \\
\text { for } \mathrm{CHD} \text { comparing } \\
\text { shortest } v \text { longest third } \\
\text { of telomere length }\end{array}$ & P value* \\
\hline \multicolumn{6}{|c|}{ Geographical location } \\
\hline Asia & 2 & 2216 & & $1.58(0.99$ to 2.53$)$ & 0.868 \\
\hline Europe & 12 & 2565 & $\longrightarrow$ & 1.63 (1.28 to 2.07$)$ & \\
\hline North America & 6 & 785 & & 1.43 (1.02 to 1.99$)$ & \\
\hline \multicolumn{6}{|l|}{ Population sourcet } \\
\hline Population based & 11 & 4229 & $\rightarrow-$ & 1.51 (1.24 to 1.85$)$ & 0.995 \\
\hline Other & 9 & 1337 & $\longrightarrow$ & $1.60(1.15$ to 2.23$)$ & \\
\hline \multicolumn{6}{|l|}{ Study quality (NOS) } \\
\hline$<8$ & 13 & 3768 & $\longrightarrow$ & 1.59 (1.23 to 2.05$)$ & 0.152 \\
\hline$\geq 8$ & 7 & 1798 & $\longrightarrow-$ & 1.53 (1.22 to 1.92$)$ & \\
\hline \multicolumn{6}{|c|}{ Mean age (years) of participants } \\
\hline$<70$ & 14 & 5193 & $\rightarrow-$ & 1.48 (1.24 to 1.75$)$ & 0.226 \\
\hline$\geq 70$ & 6 & 373 & & $1.90(1.11$ to 3.25$)$ & \\
\hline \multicolumn{6}{|c|}{ Proportion of male participants } \\
\hline$<50 \%$ & 9 & 1483 & $\rightarrow-$ & 1.31 (1.10 to 1.57$)$ & 0.453 \\
\hline$\geq 50 \%$ & 11 & 4083 & $\longrightarrow$ & 1.75 (1.33 to 2.31$)$ & \\
\hline \multicolumn{6}{|l|}{ Assay method } \\
\hline $\mathrm{qPCR}$ & 17 & 5302 & $\rightarrow-$ & $1.49(1.25$ to 1.78$)$ & 0.378 \\
\hline Other & 3 & 264 & & 1.99 (1.24 to 3.20$)$ & \\
\hline \multicolumn{6}{|c|}{ Interassay coefficient of variation } \\
\hline$\triangleleft 5 \%$ & 5 & 2759 & $\longrightarrow$ & $1.80(1.31$ to 2.47$)$ & 0.319 \\
\hline$\geq 5 \% / N R$ & 15 & 2807 & $\rightarrow-$ & $1.46(1.20$ to 1.78$)$ & \\
\hline \multicolumn{6}{|c|}{ DNA extraction method } \\
\hline QiaAMP & 6 & 1585 & $\longrightarrow$ & $1.40(1.10$ to 1.78$)$ & 0.753 \\
\hline Salting out & 8 & 1395 & $\longrightarrow$ & 1.62 (1.23 to 2.12$)$ & \\
\hline Other/NR & 6 & 2586 & 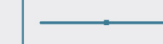 & $1.77(1.13$ to 2.75$)$ & \\
\hline \multicolumn{6}{|c|}{ No of assay replicates } \\
\hline$<3 / N R$ & 10 & 1595 & $\longrightarrow$ & $1.92(1.53$ to 2.41$)$ & 0.458 \\
\hline$\geq 3$ & 10 & 3971 & $\rightarrow-$ & 1.25 (1.05 to 1.50$)$ & \\
\hline \multicolumn{6}{|l|}{ No of cases } \\
\hline$<200$ & 12 & 922 & $\longrightarrow$ & 1.76 (1.28 to 2.42$)$ & 0.311 \\
\hline$\geq 200$ & 8 & 4644 & $\rightarrow-$ & 1.44 (1.20 to 1.74$)$ & \\
\hline \multicolumn{6}{|l|}{ Case definition } \\
\hline Fatal & 3 & 248 & & 1.48 (0.68 to 3.22$)$ & 0.580 \\
\hline Non-fatal & 9 & 3294 & $\longrightarrow$ & $1.80(1.32$ to 2.44$)$ & \\
\hline Mixed & 8 & 2024 & $\longrightarrow-$ & 1.44 (1.17 to 1.77$)$ & \\
\hline \multicolumn{6}{|c|}{ Degree of adjustment } \\
\hline$-1+$ & 8 & 674 & & 1.87 (1.16 to 3.00$)$ & 0.927 \\
\hline++ & 5 & 1237 & & 1.51 (1.11 to 2.07$)$ & \\
\hline+++ & 3 & 2519 & $\longrightarrow$ & 1.59 (1.15 to 2.22$)$ & \\
\hline \multirow[t]{2}{*}{++++} & 4 & 1136 & $\longrightarrow$ & $1.34(1.04$ to 1.74$)$ & \\
\hline & & & 2 & 4 & \\
\hline
\end{tabular}

Fig 2 Shorter telomere length and risk of coronary heart disease grouped by recorded study level characteristics. Sizes of data markers are proportional to inverse of variance of relative risk. NR=not reported; NOS=Newcastle-Ottawa scale. * $P$ values for heterogeneity from meta-regression; studies in which characteristic was not reported were not included in calculation of $P$ value; for continuous characteristics, $P$ value reflects linear test of association. + Population source of cohort or controls in case-control studies. Degree of adjustment: -/+ no adjustment or adjusted for age and/or sex, ++adjusted for age, sex, and non-lipid risk factors, +++adjusted for age, sex, BMI, diabetes, smoking, blood pressure, and lipid markers, ++++ adjusted for preceding plus $C$ reactive protein and physical activity 


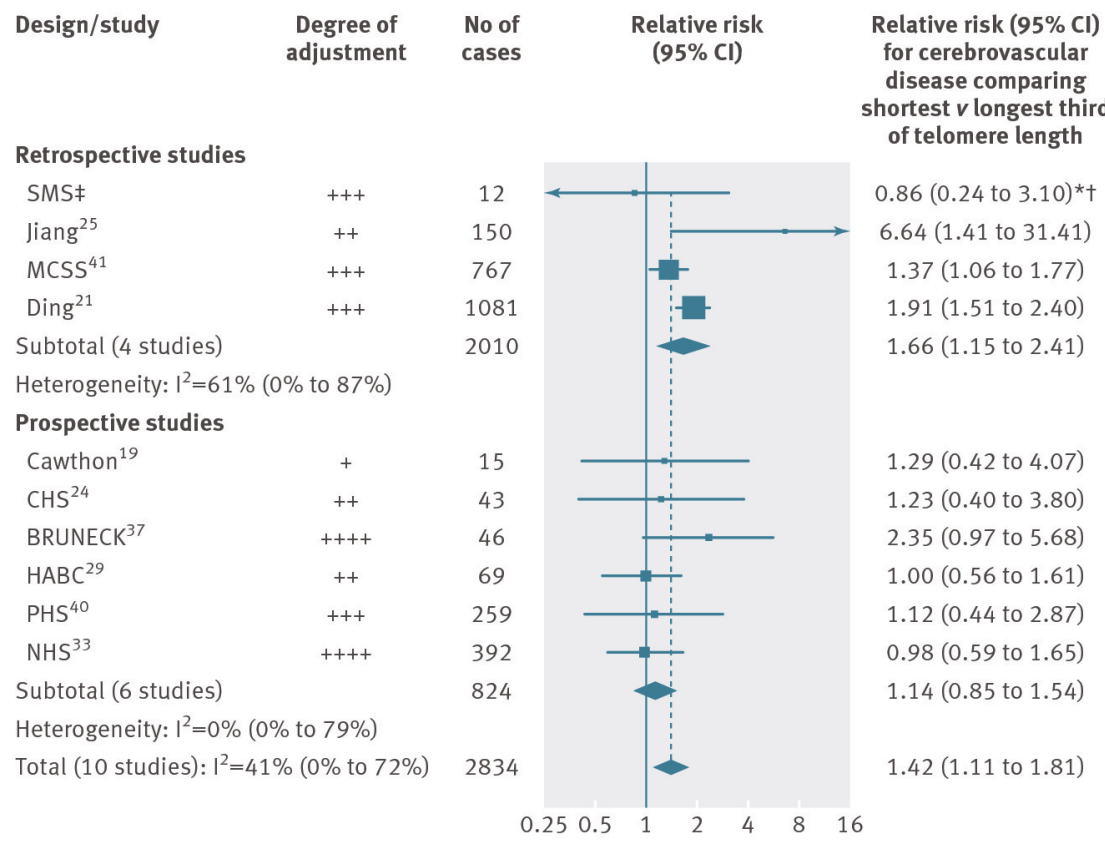

Fig 3 Shorter telomere length and cerebrovascular disease risk across 10 studies stratified by study design (see table for study acronyms). Study specific estimates were pooled with random-effects meta-analysis. Sizes of data markers are proportional to inverse of variance within study. Degree of adjustment: +adjusted for age and/or sex, ++adjusted for age, sex, and non-lipid risk factors, +++adjusted for age, sex, smoking, BMI, diabetes, blood pressure, and lipid markers, ++++ adjusted for preceding plus $\mathrm{C}$ reactive protein and physical activity. ${ }^{*}$ Calculated from mean difference in telomere length between cases and controls; †obtained through correspondence; łpreviously unpublished. Summary associations for prospective and retrospective studies were not significantly different $(P=0.15)$ 